\title{
DESIGN AND FABRICATION OF LOW COST PAPER RECYCLING EQUIPMENT
}

\section{K. DEVAKI DEVI \& M. NAGA PHANI SASTRY}

Associate Professor, Department of Mechanical Engineering, G Pulla Reddy Engineering

College, Kurnool, Andhra Pradesh, India

\begin{abstract}
Paper has become a part of human life in various aspects and it is becoming even more popular now-a-days. With the increase in consumption of paper, the problem of raw material sources is emerging. This ultimately resulted in exploitation of natural resources. Recycling of paper has become vital, since the demand for paper has increased. A survey is conducted in G Pulla Reddy Engineering College (GPREC) campus and identified the sources of waste paper. In this paper, the design and fabrication of manually operated paper recycling equipment has been presented. Recycled paper has been extracted from the equipment. H2O2 as deinking agent, Guar Gum as adhesive and Boric powder as softening agent have been added to the pulp to enhance its quality. Cost analysis has been done to analyze the budget of the equipment.

KEYWORDS: Recycling, Paper, Design, Fabrication \& Recycling Equipment
\end{abstract}

Received: Oct 23, 2017; Accepted: Nov 17, 2017; Published: Dec 01, 2017; Paper Id.: IJMPERDDEC201753

\section{INTRODUCTION}

Post-consumer paper or waste paper is one of the vital sources of raw material which can contribute considerably to reduce its imports. Recycling of paper is of same importance in industry from the perspective of environmental protection. A systematic collection and recycling of waste paper can significantly lead to reduction of solid waste generation. An estimation shows that, recycling a ton of used paper saves $70 \%$ of raw source, $60 \%$ coal reserves, $43 \%$ of energy and $70 \%$ of water as compared to that of production of new paper. Recycling of waste paper, on the other hand, is also a source of income and employment. So, implementation of suitable mechanisms to enhance the efficiency of paper recycling is the need of the hour.

According to a study, India is now able to recover only $27 \%$ of the paper consumed for re-use by the industry. This is mainly due to scarcity of scientific mechanism of collection, sorting \& transportation to the mills. In order to improve the recovery of waste paper, municipalities in association with private operators/industry may work together and should come out with a workable mechanism/model. The designing of such mechanisms and interventions lead to three major advantages.

First and foremost, the removal of post-consumer paper from the garbage cycle would considerably reduce the environmental load on the eco-system. Use of recycled fiber in the process leads to lower air emissions and energy use, which again lowers the carbon footprint of the paper industry.

It is estimated that about one-third of India's population is residing in urban areas distributed across various towns and cities, covering a total population of about 94 million households. These households generate around 2.6 million tons of dry recyclables per annum, out of which 1.3 million tons is contributed by paper only ( $50 \%$ of total dry recyclable composition), which includes newspaper and magazines also. This has the potential of 
going up substantially through integrated municipal solid waste management and installation of recycling facilities.

Paper recycling consists of several steps like collection of used paper, segregation and conversion of this used paper into new paper or other useful material. Recycling helps extend the life and usefulness of something that has already served its initial purpose by producing something that is useable. Recycling has a lot of benefits and importance not only to us humans but especially to our planet.

\section{NEED FOR RECYCLING PAPER}

Paper manufacturing industry shows a significant effect on environment. This includes tree harvesting, erosion of woodlands, water scarcity, issues of waste disposal, etc., which can be significantly reduced by recycling process. According to some studies, nearly $40 \%$ of solid waste is of paper products. So, recycling waste paper is expected to save the landfills appreciably.

\section{Recycling One Ton of Paper would Yield to following Positive Effects}

- An Indian home can be powered for approximately six months and saves nearly 7000 gallons water.

- Greenhouse effect can be reduced by one MTCE (Metric Ton of Carbon Equivalent) which leads to reduce methane emission effects.

- Extends the fiber supply and contributes to carbon sequestration.

- Save considerable landfill space.

- Reduces energy and water consumption and the disposal problems

Paper Recycling is one of the solid waste management strategies which consist of segregation of activities, gathering, processing, distribution and manufacture of products used, and the main component of modern waste management and the third part of the waste hierarchy process 3RD (Reduce, Reuse, Recycle and Disposal). The present work aims at establishment of recycling program for institutional paper waste.

\section{REVIEW OF LITERATURE}

M. A. Olutoye designed and fabricated a manually operated paper recycling machine. The fabricated plant constituted six major component units that include the disc refiner, the Hydro-pulper, the head box, the felt conveyor, the driers and the rollers. From the results of experimental analysis carried out on the study, they discovered that for $0.1 \mathrm{~kg}$ of used paper fed into refiner, about $7000 \mathrm{ml}$ of water is required to de-fiber it and about $0.2 \mathrm{~kg}$ of starch adhesive is required. The fabricated machine was capable of producing $7.6 \mathrm{~kg}$ of recycled paper from $10 \mathrm{~kg}$ of used paper.

R. A. Venditti, O. J. Rojas and few other scholars did a research on how to evaluate new types of surfactants (sugar and protein based) for deinking of recycled paper using flotation process. The authors applied green chemistry approaches to minimize the impact of deinking agents on environment. Vrushabh R. Rathod, Saurath \& Nitin, in their Design of "Manually Operated Portable Paper Recycling Machine" mentioned that in any educational institution, waste paper generation is quiet common, where there is a large scope for recycling and using them as craft papers or registers. 


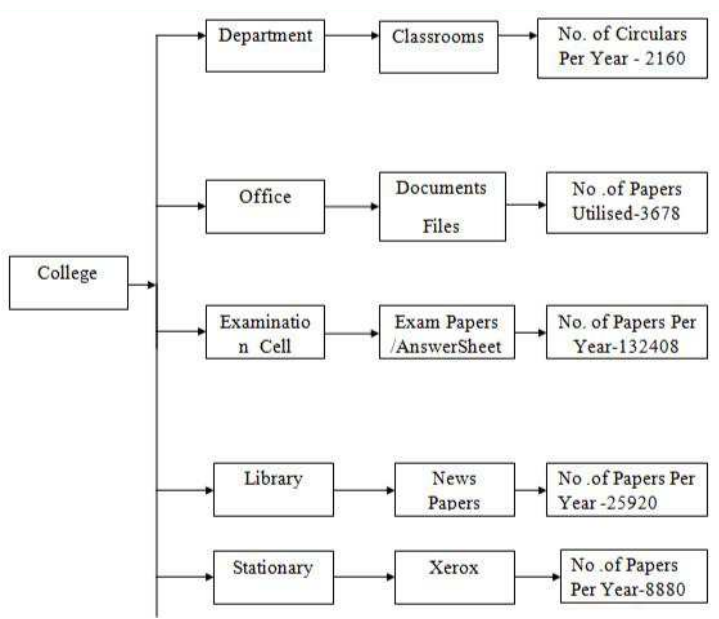

Figure 1: Sources of Waste Paper in GPREC (Source: Experimental Survey)

\section{PROCESS OF PAPER RECYCLING}

Pulp and paper industry uses varieties of wood as a primary raw material to make different types of paper with different specific properties for different applications. The process of paper making/recycling is accomplished by the following steps:

- Pulping and bleaching

- Paper making and

- $\quad$ finishing

\section{Pulping and Bleaching}

Paper contains wood cellulose fibers. First, the wood material/used paper is crushed and dissolved in to pulp which results in a mass of individual fibers. Then the pulp is washed and filtered to remove foreign residues. The remaining water in the pulp is removed by pressing the pulp, which is then directly used or bleached for imparting whiteness and brightness.

For recycling, the paper collected from various places is categorized and sorted using conveyor belts. Deinking is necessary for waste paper recycling since it contains written ink, graph marks, etc. deinking is done by two methods washing and flotation.

Washing process- a hydro-pulper is used for separating the fibers from the paper web by agitating with water and making slurry. Any undesirable material can be removed by centrifugal screening, through which most of the ink is drained of through ink screens. Sickies (unwanted adhesive particles) are then removed by fine screening process.

Flotation process - the used paper is dissolved and made into slurry and chemical surfactants are added to produce froth floating on the pulp. This froth which carries ink and unwanted foreign particles, is then blown away from the slurry before the bubbles break. The pulp cleaned in this way is then subjected to bleaching to make high quality paper. Bleaching process imparts absorption capacity to the paper. ECF (elemental chlorine-free) pulping using chlorine dioxide is now the dominant technology worldwide. 


\section{Papermaking}

On the paper machine, more water is added to produce a fiber suspension of as little as 1-to-10 parts fiber to 1000 parts water and the resulting mixture is passed into a head-box which squirts it through a thin, horizontal slit across the full machine width (typically $2-6 \mathrm{~m}$ ) on to a moving, endless wire mesh. The water is then removed on this wire section by a mixture of gravity and suction in a process known as sheet formation where the fibers start to spread and consolidate into a thin mat, which is almost recognizable as a layer of paper on top of the wire mesh. This web of wet paper is then lifted from the wire mesh and squeezed between a series of presses where its water content is lowered to about $50 \%$.

\section{DESIGN OF PAPER RECYCLING EQUIPMENT}

\section{Hydropulper}

Paper pulper is used, for crushing virgin pulp (slabs or sheets), waste paper processing, machine broke, deinking and pulp purification. It disintegrates the fiber by the action of mechanical operation. Among, the raw materials waste paper processing is significant. Hydropulper can be designed, to operate at high (20\%-40\%), medium or low consistency $(3 \%-5 \%)$. They can have bottom entry, side entry or top entry rotors.

\section{Design Calculations and Modelling}

$$
\begin{aligned}
& \text { Mass of waste paper }(\mathrm{m})=70 \mathrm{~kg} \\
& \text { Density of the pulp }(\ell)=1.732 \mathrm{~g} / \mathrm{cm}^{3} \\
& \text { Volume of the pulp }\left(\mathrm{V}_{\mathrm{p}}\right)=\mathrm{m} / \ell \\
& \mathrm{V}_{\mathrm{p}}=70 * 10^{3} / 1.732=40416 \mathrm{~cm}^{3} \\
& \text { Volume of the Hydropulper } \mathrm{V}_{\mathrm{H}}=\mathrm{V}_{\mathrm{p}}+0.3 \mathrm{~V}_{\mathrm{p}}=(1.3) \mathrm{V}_{\mathrm{p}}=52540 \mathrm{~cm}^{3} \\
& \text { the shape of Hydropulper is cylinder, } \mathrm{V}_{\mathrm{H}}=\pi / 4 \mathrm{D}^{2} \mathrm{~h} \text { Let, } \mathrm{h}=50 \mathrm{~cm} \\
& \mathrm{D}=37 \mathrm{~cm}
\end{aligned}
$$

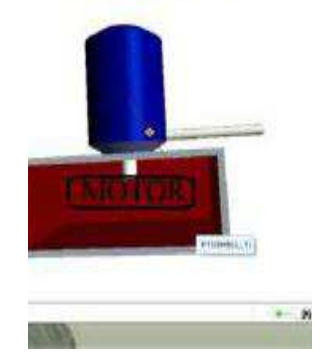

Figure 2: Isometric Front View of Hydro Pulper

\section{Design of Blade}

Diameter of blade $(\mathrm{Db})=0.5+\mathrm{D}=18.5 \mathrm{~cm}$

Height of the blade from base of the cylinder $=5 \mathrm{~cm}$.

\section{Univat}

Univat plays a crucial role in paper recycling process. After completion of pulp preparation the pulp is placed on 
Univat box. The Univat is submerged 3/4 Univat tank. It is connected to lifting bars with the help of chains. Here, the pulp is poured into the Univat box and mixed thoroughly. After completion of mixing, the Univat box is lifted with help of lever mechanism by applying force on it. The flat wire screen is having uniform thickness sheet of paper pulp on the screen, water starts to drain from the pulp and the recycled fibers begin to bond together to form a watery sheet. The paper pulp is separated with help of cotton cloths and placed one by one in order. The number of paper sheets are moved to screw-press to squeeze cut more water by applying the human effort. The Univat tank is made of 18 " MS guage sheet material. The long sheet is made into five pieces with the following dimensions:

$$
\text { Base }-42^{\prime \prime} \times 30^{\prime \prime} \quad \text { Side }-42^{\prime \prime} \times 18^{\prime \prime} \quad \text { Width }-30^{\prime \prime} \times 18^{\prime \prime}
$$

The long sheet is cut into pieces by the Gas cutting which includes gases like LPG and Oxygen. The five pieces of sheet are used for base, sides and width of a rectangular and made a rectangular tank. The sheets are welded to make tank with the help of Arc welding with Voltage 120 to 180 volts. The tank is made to stand with the support of four legs.

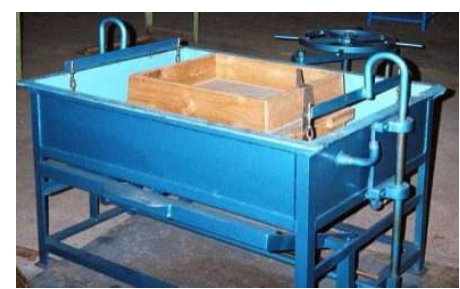

Figure 3: Fabricated UNIVAT Tank

\section{De-Inking}

In a Univat the deinking process is to be done. At initially the pulp is mixed with the water. Sometimes the pulp must undergo a pulp laundering operation called deinking to remove minting ink.

\section{Screw-Press}

Screw press is used to separate liquids from solids. A screw press is a type of machine press in which the ram is driven up and down by a screw. The screw shaft can be driven by a handle or wheel. It works by using a coarse screw to convert the rotation of handle or drive-wheel into a small downward movement of great force.

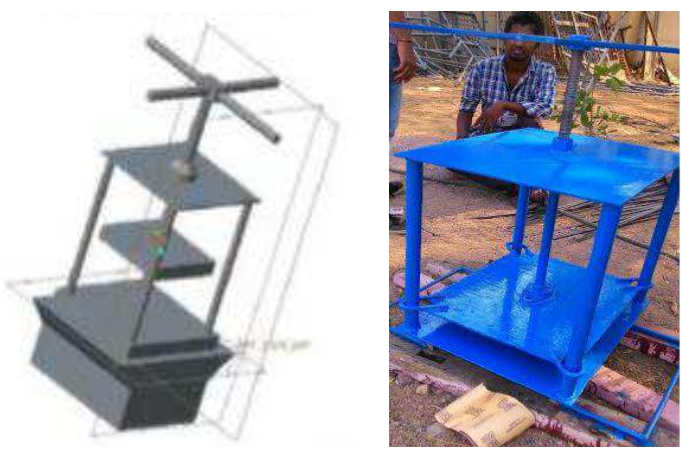

Figure 4: Screw Press Design and Fabricated Model

\section{COLLECTION OF WASTE PAPER}

The waste paper generated in various departments, office, library, stationary, examination cell is identified and collected for the recycling of waste paper and their by utilizing waste generated in the campus effectively. 


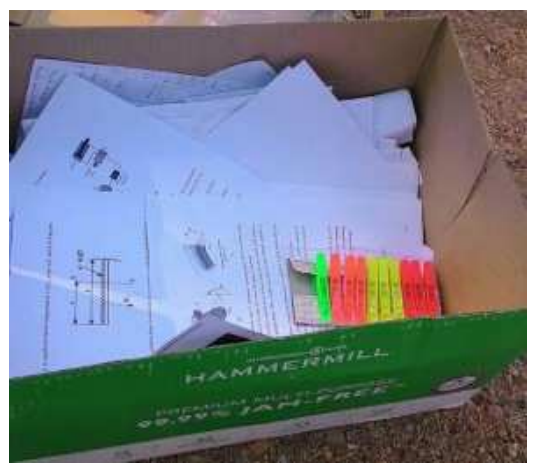

Figure 5: Collection of Waste Paper within the Campus GPREC

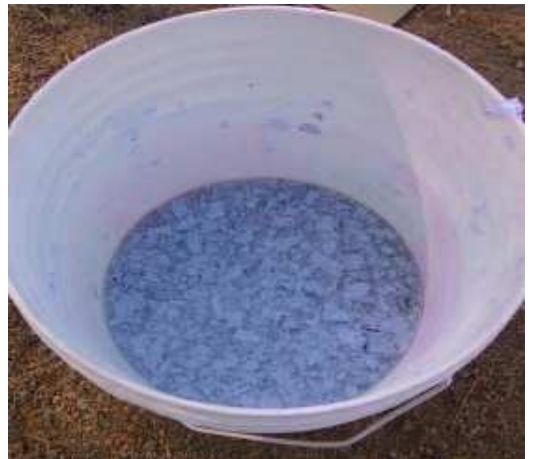

Figure 6: Soaking of Waste Paper Collected

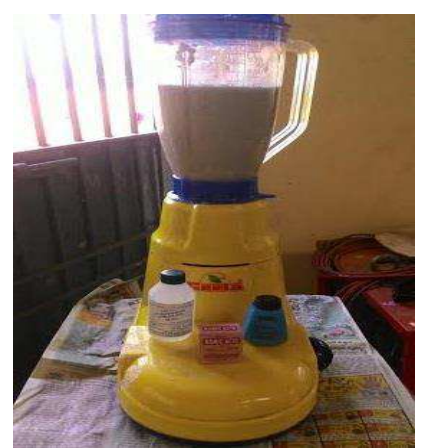

Figure 7: Pulping of Waste Paper

The collected waste paper is made into small pieces and made to rest in water for the entire day for making pulp. The Hydro pulper, which is used to make pulp fibers in the recycling process, is replaced with the blender. After pulping process, the pulp is deinked. The deinking of pulp is carried out in a container which consists of $\mathrm{H} 2 \mathrm{O} 2$, Boric Powder and Gaur Gum. One liter of pulp that is taken for the deinking utilizes $10 \mathrm{ml}$ of H2O2, 5 gm of Boric Powder and $10 \mathrm{ml}$ of Gaur Gum. The above figure 5.4 shows pulping of paper waste collected and adding adhesives to the pulp collected in the container for strengthening of fibers.

\section{Paper Extraction}

The pulp made is placed on Univat box. The Univat box is submerged $3 / 4$ Univat tank. It is connected to lifting bars with the help of chains. Here, the pulp is poured in to the Univat box and mixed thoroughly. After completion of mixing the Univat box is lifted with help of lever mechanism, by applying force on it. The flat wire screen which is having uniform thickness sheet of paper pulp on the screen, water starts to drain from the pulp and the recycled fibers begin to bond together to form a watery sheet.

The paper pulp is separated with help of cotton cloth and placed one by one. The screw press squeezes the material against a screen or filter, and the liquid is collected through the screen. After the water is squeezed, the outcome is dried and made into pieces or sheet of paper of different sizes. 


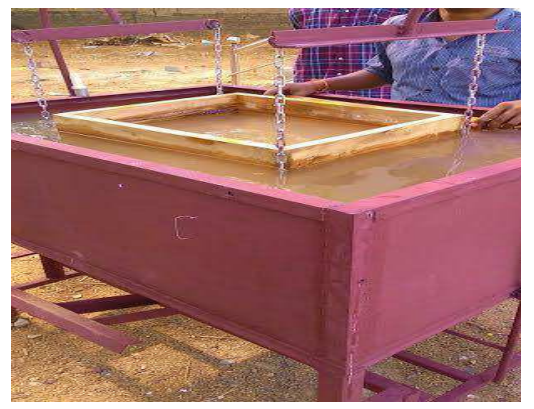

Figure 8: Making Sheet of Pulp

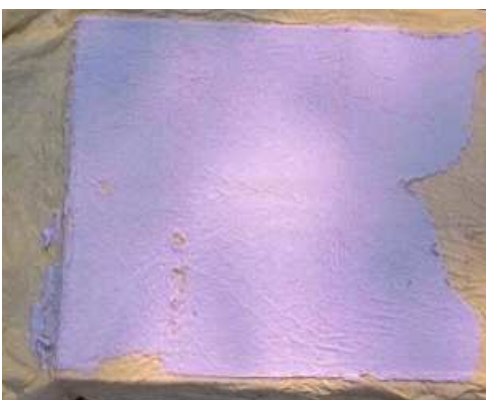

Figure 9: Recycled Paper

The above figure 5.11shows the output of the Paper Recycling Process done within the campus GPREC in the view of effective utilization of waste paper generated in the campus.

\section{COST ANALYSIS}

Table 1: Cost Analysis

\begin{tabular}{|l|c|c|}
\hline \multicolumn{1}{|c|}{ Raw Material } & Dimension & Cost \\
\hline 18 " MS Flat guage sheet & $78.4 " \times 78.4 "$ & $5000 /-$ \\
\hline 1 ' MS Hollow circular & $78.4 "$ & $1000 /-$ \\
\hline 5mm MS Flat Sheet & $21^{\prime \prime} \times 18^{\prime \prime}$ & $1000 /-$ \\
\hline 5MM MS Flat Sheet & $19 " \times 16 "$ & $500 /-$ \\
\hline Belgium circular screw and & $27.5^{\prime \prime}$ & $1000 /-$ \\
\hline Pedestrial Bearing & & $400 /-$ \\
\hline 16 mm circular cross & $157.4 "$ & $500 /-$ \\
\hline Miscellaneous & & $1600 /-$ \\
\hline Total Cost & & $\mathbf{1 2 0 0 0 / -}$ \\
\hline
\end{tabular}

\section{RESULT \& CONCLUSIONS}

Recycling of waste paper is beneficial not only from economic point of view, but also for the Protection of Environment. It promotes conservation of one of our very important natural resource trees. Considering this, a small scale manually operated recycling machine has been designed and fabricated, which can recycle waste paper for various productive purposes.

\section{REFERENCES}

1. M. A. Olutoye, Leonardo Electronic Journal of Practices and Technologies 7, 2005, pp. 49.

2. Metin YilmazEuropean Journal of Accounting Auditing and Finanace Research 3(4), 2015, pp.58.

3. Vrushabh, Saurabh, Nitin., International Journal on Recent and Innovation Trends in Computing and Communication, 3(2), 2015 , pp.50.

4. Mohammad Aslam Khan, Management of Paper Industries in India:-Prospects and Problems, International Journal of Business Management \& Research (IJBMR), Volume 2, Issue 3, August - September 2012, pp. 54-62

5. Shanmugapriya, Vanisree, Kiruthika., International Journal of Advanced Research, 3(7), 2015, pp.77.

6. Dr. Fauzia Siddiqui, HarshadPatil, Swapnil Raut, OmkarWadake, Swapnil Tandel, International Journal of Scientific \& Engineering Research, 8(3), 2017, pp.18. 
